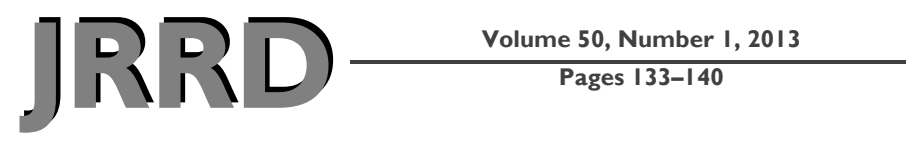

\title{
Comparing routine neurorehabilitation program with trunk exercises based on Bobath concept in multiple sclerosis: Pilot study
}

\author{
Ilke Keser, PhD, PT; ${ }^{1 *}$ Nuray Kirdi, Prof PhD, PT $;^{2}$ Aydin Meric, PhD, PT; ${ }^{2}$ Asli Tuncer Kurne, Assoc Prof MD $;^{3}$ \\ Rana Karabudak, Prof $\mathrm{MD}^{\mathbf{3}}$ \\ ${ }^{1}$ Department of Physical Therapy and Rehabilitation, Faculty of Health Sciences, Gazi University Ankara, Turkey; \\ Departments of ${ }^{2}$ Physical Therapy and Rehabilitation, Faculty of Health Sciences, and ${ }^{3}$ Neurology, Faculty of Medi- \\ cine, Hacettepe University, Ankara, Turkey.
}

\begin{abstract}
This study compared trunk exercises based on the Bobath concept with routine neurorehabilitation approaches in multiple sclerosis (MS). Bobath and routine neurorehabilitation exercises groups were evaluated. MS cases were divided into two groups. Both groups joined a $3 \mathrm{~d} / \mathrm{wk}$ rehabilitation program for $8 \mathrm{wk}$. The experimental group performed trunk exercises based on the Bobath concept, and the control group performed routine neurorehabilitation exercises. Additionally, both groups performed balance and coordination exercises. All patients were evaluated with the Trunk Impairment Scale (TIS), Berg Balance Scale (BBS), International Cooperative Ataxia Rating Scale (ICARS), and Multiple Sclerosis Functional Composite (MSFC) before and after the physiotherapy program. In group analysis, TIS, BBS, ICARS, and MSFC scores and strength of abdominal muscles were significantly different after treatment in both groups $(p<0.05)$. When the groups were compared, no significant differences were found in any parameters $(p>0.05)$. Although trunk exercises based on the Bobath concept are rarely applied in MS rehabilitation, the results of this study show that they are as effective as routine neurorehabilitation exercises. Therefore, trunk exercises based on the Bobath concept can be beneficial in MS rehabilitation programs.
\end{abstract}

Key words: Berg Balance Scale, Bobath, exercise, International Cooperative Ataxia Rating Scale, multiple sclerosis, Multiple Sclerosis Functional Composite, neurorehabilitation, physiotherapy, trunk control, Trunk Impairment Scale.

\section{INTRODUCTION}

Multiple sclerosis (MS) is a lifelong disease that must be supported by continuous physiotherapy to decrease adverse effects of the symptoms. Several studies have stressed the beneficial effects of exercises on the treatment of MS-related clinical symptoms [1-2]. Therapeutic exercises can accelerate the spontaneous restoration of central nervous system damage [3].

Since physiotherapy and rehabilitation are carried out over a long period of time, exercise variation is needed according to different requirements. When studies about physiotherapy approaches for MS populations are examined, it is observed that most routine neurorehabilitation programs concentrate on limb exercises. Therefore, in routine

\footnotetext{
Abbreviations: $\mathrm{BBS}=$ Berg Balance Scale, EDSS $=$ Expanded Disability Status Scale, ICARS = International Cooperative Ataxia Rating Scale, MS = multiple sclerosis, MSFC = Multiple Sclerosis Functional Composite, NHPT $=$ Nine-Hole Peg Test, PASAT $=$ Paced Auditory Serial Addition Test, T25WT $=$ Timed 25-Foot Walk Test, TIS = Trunk Impairment Scale.

*Address all correspondence to Ilke Keser, PhD, PT; Gazi University, Faculty of Health Sciences, Department of Physical Therapy and Rehabilitation, Beşevler/Ankara, Turkey; +903122162635; fax: +903122162636.

Email: ilkekeser@yahoo.com

http:/dx.doi.org/10.1682/JRRD.2011.12.0231
} 
MS rehabilitation, most physiotherapy programs focus on the limbs. Through limb recovery, they aim to gain functions [4].

According to Davies, loss of selective trunk control is clearly associated with limitations in balance, gait, and arm and hand function [5].

Despite many studies indicating effects of different exercise approaches, few have concentrated on the effectiveness of trunk exercises in the MS population. Besides the fact that trunk performance is directly related to disability, measuring the trunk is important in the examination and treatment of people with MS [6].

The trunk has a critical role in the organization of postural reactions [7-8]. The Bobath approach underlines the critical role of postural stability [9]. Co-contraction of the trunk flexors and extensor muscles has been found to increase the stability of the spine [10]. Postural stability is necessary for selective movements and balance. Furthermore, selective movement of the trunk and limbs are independent and interactive with a postural control mechanism. The effectiveness of trunk-specific rehabilitation has been shown for different neurological diseases, including stroke [11] and Parkinson disease [12]. However, there is little data focused on MS [13-14]. The trunk can be affected at any stage of the disease, which may affect the level of disability.

This study was designed to demonstrate the role of trunk exercises in MS rehabilitation. Our aim was to compare the effectiveness of trunk exercises based on the Bobath concept with routine neurorehabilitation approaches in MS.

\section{METHODS}

\section{Participants}

MS patients with a diagnosis of clinically definite MS as per the McDonald criteria were enrolled in the study. Inclusion criteria were (1) no relapse in the past 2 mo, (2) $0.5-5.5$ points on the Expanded Disability Status Scale (EDSS) [15], and (3) 3 or less on the Modified Ashworth Scale [8] for any muscle group. The participants were included in the study after they signed the informed consent.

Patients with relapses, a recent surgery, cognitive or psychological dysfunctions, or a diagnosis of any other systematic disease were excluded. The patients were evaluated and treated by the same doctors and physio- therapist specialized in MS. All the tests were performed before treatment and repeated after $8 \mathrm{wk}$ of treatment.

\section{Interventions}

The study was an 8 wk-long outpatient program [16]. The patients were assigned to the study or control groups randomly. The design of the study was randomized control. The groups were formed so as to eliminate the effects of mean disability level and sex. The program for both groups included 60 min sessions three times a week. The sessions were held on alternate days to eliminate the accumulation of fatigue. Therapy included resting periods to prevent any increase in body temperature and fatigue.

The foundation for practice was based on the experience of the physiotherapist and took patients' needs and expectations into consideration [17]. The physiotherapy programs consisted of exercises performed at the participants' individual functional levels, which were developed dynamically in parallel with improvements.

The control group $(n=10)$ was given a routine neurorehabilitation program that consisted of posture, mat, coordination, balance, walking, stepping and movement control, and strengthening exercises. Upper- and lower-limb patterns were performed to improve muscle strength and movement control.

The study group $(n=10)$ performed posture, mat, coordination, balance, walking, stepping and movement control, and strengthening exercises and trunk exercises based on the Bobath concept (designed according to the International Bobath Instructors Training Association course). ${ }^{*}$

\section{Outcome Measures}

Assessments were made in the same place, time, and order by the same physiotherapist who applied the exercises at the beginning and end of the physiotherapy program in order to prevent changes as a result of these variables.

Trunk control was assessed by the Trunk Impairment Scale (TIS) [6], which evaluates static and dynamic stability and coordination of trunk. Balance was evaluated by the Berg Balance Scale (BBS) [7,18-20], which consists of 14 standardized subtests scored on 5-point scales

\footnotetext{
${ }^{*}$ Course information: Assessment and treatment of adult hemiplegiaThe Bobath concept. Trainer: Elia Panturin, Senior Instructor; International Bobath Instructors Training Association (15-22.04.2006 and 22-28.06.2006). School of Physiotherapy and Rehabilitation, Hacettepe University, Ankara, Turkey.
} 
$(0-4)$, with a maximum (best) score of 56 . Coordination was evaluated by the International Cooperative Ataxia Rating Scale (ICARS) [21], which has been found to be valid and safe in degenerative ataxia patients [22-24]. A pilot study suggested that the ICARS is a useful tool to assess balance in MS patients [25]. To measure functional changes, we applied the Multiple Sclerosis Functional Composite (MSFC) [26-27]. The MSFC assesses upper-motor function with the Nine-Hole Peg Test (NHPT), lower-motor function with the Timed 25-Foot Walk Test (T25FT), and cognitive functions with the Paced Auditory Serial Addition Test. (PASAT).

\section{Data Analysis}

In the data analysis, nonparametric approaches were used because of the small sample size. The Wilcoxon signed-rank test was used to compare data within the groups. The differences between groups were examined by the Mann-Whitney $\mathrm{U}$ test; $\alpha=0.05$ was selected as the bias level for all analyses. The $p$-values equal to or lower than this were considered statistically important (significant), whereas higher values were defined as statistically unimportant (insignificant). Arithmetic mean \pm standard deviation values were used in displaying the descriptive statistics.

\section{RESULTS}

\section{Participant Characteristics}

We enrolled 23 patients in the study. In the follow up, 1 had to leave the study at the 16th session of the treatment because of a change in medication, 1 did not want to continue because of psychological problems, and 1 had scheduling problems. Therefore, 20 patients completed the entire study. There were six women and four men in each group. Mean disability level as assessed by the EDSS was $2.80 \pm 0.88$ points for the experimental group and $2.85 \pm 0.81$ points for the control group. The characteristics of participants are given in Table 1.

\section{Trunk Control, Balance, Coordination, and Functional State Assessments for Each Group}

The TIS and its subtests (static-dynamic sitting balance and coordination) were analyzed individually. Both the TIS and its subtests increased significantly in both groups for the pre- and posttreatment periods $(p<0.05)$
Table 1.

Patient characteristics (mean \pm standard deviation, unless otherwise indicated).

\begin{tabular}{lcc}
\hline \multicolumn{1}{c}{ Characteristic } & Study $(\boldsymbol{n}=\mathbf{1 0})$ & Control $(\boldsymbol{n}=\mathbf{1 0})$ \\
\hline Age $(\mathrm{yr})$ & $33.60 \pm 11.96$ & $43.60 \pm 1.14$ \\
Sex (Women/Men) & $6 / 4$ & $6 / 4$ \\
EDSS (Score) & $2.80 \pm 0.88$ & $2.85 \pm 0.81$ \\
Disease Duration (yr) & $4.45 \pm 4.45$ & $8.25 \pm 5.28$ \\
\hline EDSS = Expanded Disability Status Scale. & \\
\hline
\end{tabular}

(Table 2), except for static sitting balance of the experimental group.

BBS changed significantly for each group between the pre- and posttreatment periods $(p<0.05)$ (Table 2).

The ICARS and its subtests were analyzed individually. The decrease in ICARS 1 (posture and gait), ICARS 2 (kinetic functions), and total ICARS scores were statistically significant in both groups for the pre- and posttreatment periods $(p<0.05)$. No difference was detected for ICARS 3 and 4 in the pre- and posttreatment periods (Table 2).

The MSFC test and its subtests were analyzed. The NHPT and total MSFC scores of the experimental group and the T25FT and MSFC scores of the control group changed significantly. The PASAT scores did not change in either of the groups (Table 3).

\section{Comparison Between Groups}

No significant differences were found between groups for the ICARS, MSFC, TIS, and BBS (Table 4).

\section{DISCUSSION}

MS is a life-long disease for which physiotherapy is thought to be crucial and beneficial [28]. In clinical practice, it is difficult to keep patients motivated continuously. For this reason, physiotherapists have to vary exercises to encourage patients to develop regular exercise habits and keep them motivated while carrying out main treatment goals. As a result, new approaches are demanded. In recent literature, physiotherapy based on the Bobath concept has been used to improve functions in MS patients [14].

Bobath-based exercises have recently been recommended for use in MS rehabilitation [14]. According to the Bobath concept, the trunk has a key role in functional recovery. There are many exercises focused on the trunk 
Table 2.

Trunk Impairment Scale (TIS), Berg Balance Scale (BBS), and International Cooperative Ataxia Rating Scale (ICARS) scores for study (S) and control (C) groups $(n=10$ each group).

\begin{tabular}{|c|c|c|c|c|c|}
\hline \multirow{2}{*}{ Measure } & \multirow{2}{*}{ Group } & \multicolumn{2}{|c|}{ Mean \pm Standard Deviation } & \multirow{2}{*}{$\mathbf{Z}$} & \multirow{2}{*}{$p$-Value } \\
\hline & & Before Treatment & After Treatment & & \\
\hline \multirow[t]{2}{*}{ Static Sitting Balance } & $\mathrm{S}$ & $6.10 \pm 1.28$ & $6.20 \pm 1.47$ & -0.27 & 0.78 \\
\hline & $\mathrm{C}$ & $9.30 \pm 1.70$ & $6.70 \pm 0.48$ & -2.041 & $0.04^{*}$ \\
\hline \multirow[t]{2}{*}{ Dynamic Sitting Balance } & $\mathrm{S}$ & $5.00 \pm 2.30$ & $8.00 \pm 2.30$ & -2.53 & $0.01^{*}$ \\
\hline & $\mathrm{C}$ & $4.90 \pm 1.91$ & $7.30 \pm 1.94$ & -2.14 & $0.03^{*}$ \\
\hline \multirow[t]{2}{*}{ Coordination } & $\mathrm{S}$ & $2.80 \pm 1.39$ & $4.80 \pm 1.39$ & -2.39 & $0.03^{*}$ \\
\hline & $\mathrm{C}$ & $2.40 \pm 0.84$ & $4.40 \pm 1.34$ & -2.75 & $0.00^{*}$ \\
\hline \multirow[t]{2}{*}{ TIS } & S & $13.90 \pm 2.76$ & $19.20 \pm 4.15$ & -2.67 & $0.00^{*}$ \\
\hline & $\mathrm{C}$ & $12.60 \pm 2.54$ & $18.00 \pm 3.74$ & -2.44 & $0.01^{*}$ \\
\hline \multirow[t]{2}{*}{ BBS } & S & $49.2 \pm 5.35$ & $53.10 \pm 2.88$ & -2.403 & $0.01^{*}$ \\
\hline & $\mathrm{C}$ & $46.2 \pm 4.96$ & $50.70 \pm 4.37$ & -2.403 & $0.01^{*}$ \\
\hline \multirow[t]{2}{*}{ ICARS 1} & $\mathrm{~S}$ & $7.70 \pm 4.29$ & $4.20 \pm 3.32$ & -2.67 & $0.00^{*}$ \\
\hline & $\mathrm{C}$ & $8.00 \pm 2.98$ & $5.60 \pm 2.79$ & -2.68 & $0.00^{*}$ \\
\hline \multirow[t]{2}{*}{ ICARS 2} & $\mathrm{~S}$ & $6.90 \pm 2.13$ & $4.10 \pm 3.84$ & -2.32 & $0.02^{*}$ \\
\hline & $\mathrm{C}$ & $9.00 \pm 3.39$ & $5.70 \pm 3.23$ & -2.25 & $0.02^{*}$ \\
\hline \multirow[t]{2}{*}{ ICARS 3} & $\mathrm{~S}$ & $0.80 \pm 0.91$ & $0.30 \pm 0.67$ & -1.63 & 0.10 \\
\hline & $\mathrm{C}$ & $1.50 \pm 1.43$ & $0.90 \pm 0.99$ & -1.73 & 0.08 \\
\hline \multirow[t]{2}{*}{ ICARS 4} & S & $1.60 \pm 1.26$ & $1.80 \pm 1.47$ & -0.55 & 0.57 \\
\hline & $\mathrm{C}$ & $1.80 \pm 1.22$ & $1.70 \pm 1.15$ & -1.00 & 0.31 \\
\hline \multirow[t]{2}{*}{ Total ICARS } & S & $17.00 \pm 6.54$ & $10.40 \pm 7.76$ & -2.80 & $0.00^{*}$ \\
\hline & $\mathrm{C}$ & $20.30 \pm 4.99$ & $13.90 \pm 4.50$ & -2.80 & $0.00^{*}$ \\
\hline
\end{tabular}

Table 3.

Multiple Sclerosis Functional Composite (MSFC) scores for study (S) and control (C) groups ( $n=10$ each group).

\begin{tabular}{|c|c|c|c|c|c|}
\hline \multirow{2}{*}{ Measure } & \multirow{2}{*}{ Group } & \multicolumn{2}{|c|}{ Mean \pm Standard Deviation } & \multirow{2}{*}{$\mathbf{Z}$} & \multirow{2}{*}{$p$-Value } \\
\hline & & Before Treatment & After Treatment & & \\
\hline \multirow[t]{2}{*}{ NHPT (s) } & $\mathrm{S}$ & $39.62 \pm 43.40$ & $37.19 \pm 43.05$ & -2.70 & $0.007^{*}$ \\
\hline & $\mathrm{C}$ & $27.38 \pm 3.52$ & $25.84 \pm 4.28$ & -1.37 & 0.16 \\
\hline \multirow[t]{2}{*}{ T25FT (s) } & $\mathrm{S}$ & $12.40 \pm 2.74$ & $10.49 \pm 1.84$ & -2.70 & 0.07 \\
\hline & $\mathrm{C}$ & $15.41 \pm 5.34$ & $13.59 \pm 4.10$ & -2.80 & $0.005^{*}$ \\
\hline \multirow[t]{2}{*}{ PASAT (correct) } & S & $43.30 \pm 7.77$ & $47.30 \pm 9.97$ & -1.31 & 0.19 \\
\hline & $\mathrm{C}$ & $33.60 \pm 12.40$ & $37.00 \pm 13.44$ & -1.72 & 0.85 \\
\hline \multirow[t]{2}{*}{ Total MSFC (points) } & $\mathrm{S}$ & $-0.57 \pm 0.54$ & $-0.26 \pm 0.53$ & -2.49 & $0.01^{*}$ \\
\hline & $\mathrm{C}$ & $-0.94 \pm 0.46$ & $-0.68 \pm 0.54$ & -2.39 & $0.01^{*}$ \\
\hline
\end{tabular}

${ }^{*} p<0.05$ (Wilcoxon Sign Test).

NHPT $=$ Nine-Hole Peg Test, PASAT $=$ Paced Auditory Serial Addition Test, T25FT $=$ Timed 25-Foot Walk Test.

in the Bobath concept. The trunk can be affected at any stage of the disease, which may affect level of disability. The aim of this study was to compare the effectiveness of trunk exercises based on the Bobath concept with routine neurorehabilitation approaches in MS.
In the current study, the effect of trunk-focused rehabilitation was assessed by scales measuring trunk impairment, balance, ataxia, and functional status. Trunk impairment was evaluated by shortening and elongation of the trunk appropriately, with selected movements for 
Table 4.

Analysis between for study (S) and control (C) groups ( $n=10$ each group).

\begin{tabular}{|c|c|c|c|c|c|}
\hline \multirow{2}{*}{ Measure } & \multicolumn{2}{|c|}{ Mean \pm Standard Deviation } & \multirow{2}{*}{$\mathbf{U}$} & \multirow{2}{*}{$\mathbf{Z}$} & \multirow{2}{*}{$p$-Value } \\
\hline & Study & Control & & & \\
\hline Static Sitting Balance & $0.10 \pm 0.99$ & $1.40 \pm 1.57$ & 28.50 & -1.83 & 0.06 \\
\hline Dynamic Sitting Balance & $3.00 \pm 2.05$ & $2.40 \pm 2.83$ & 43.00 & -0.53 & 0.59 \\
\hline Coordination & $2.00 \pm 1.76$ & $2.00 \pm 1.05$ & 50.00 & 0.00 & $>0.99$ \\
\hline TIS & $5.30 \pm 2.62$ & $5.40 \pm 4.81$ & 48.00 & -0.15 & 0.87 \\
\hline BBS & $3.90 \pm 4.04$ & $4.50 \pm 4.67$ & 45.50 & -0.34 & 0.73 \\
\hline ICARS 1 & $-3.50 \pm 2.22$ & $-2.40 \pm 1.71$ & 34.50 & -1.18 & 0.23 \\
\hline ICARS 2 & $-2.80 \pm 2.85$ & $-3.30 \pm 4.21$ & 47.50 & -0.19 & 0.84 \\
\hline ICARS 3 & $-0.50 \pm 0.84$ & $-0.60 \pm 0.96$ & 45.50 & -0.37 & 0.70 \\
\hline ICARS 4 & $0.20 \pm 1.03$ & $-0.10 \pm 0.31$ & 37.00 & -1.29 & 0.19 \\
\hline Total ICARS & $-6.60 \pm 4.59$ & $-6.40 \pm 4.59$ & 49.50 & -0.03 & 0.97 \\
\hline NHPT (s) & $-1.21 \pm 0.73$ & $-0.77 \pm 1.42$ & 31.00 & -1.30 & 0.15 \\
\hline T25FT (s) & $-1.91 \pm 1.85$ & $-1.81 \pm 1.49$ & 48.50 & -0.11 & 0.91 \\
\hline PASAT (true number) & $-4.00 \pm 7.80$ & $3.40 \pm 5.69$ & 45.00 & -0.38 & 0.70 \\
\hline Total MSFC & $0.30 \pm 0.28$ & $0.26 \pm 0.25$ & 39.00 & -0.49 & 0.62 \\
\hline
\end{tabular}

* $p<0.05$ (Mann-Whitney U Test).

BBS $=$ Berg Balance Scale, ICARS $=$ International Cooperative Ataxia Rating Scale, MSFC $=$ Multiple Sclerosis Functional Composite, NHPT $=$ Nine-Hole Peg Test, PASAT $=$ Paced Auditory Serial Addition Test, T25FT $=$ Timed 25-Foot Walk Test, TIS $=$ Trunk Impairment Scale.

both upper and lower parts, and movements without compensation [29]. TIS evaluates static and dynamic sitting balance and coordination.

In this study, both groups' total TIS scores and dynamic sitting balance improved similarly. Static sitting balance improved significantly in the control group only. This could be explained by the important role of the trunk in stabilization and intended limb movements [30-32].

In the present study, balance scores of both groups increased significantly by the end without any difference between groups. This led us to think that the routine rehabilitation exercises and the trunk exercises based on the Bobath concept had similar effects on balance.

Because of the significant change in the ICARS 1 (posture and gait) and ICARS 2 (kinetic functions) subtests and total ICARS score and similar improvement in both groups, both approaches are thought to have similar effects on coordination.

The functional status of both groups improved significantly. However, in some subtests there were little differences. The control group, which performed more limb exercises, had significant improvements in walking tests. It was not surprising to observe that control of the lower limbs was found to be very important for gait.

Both groups demonstrated improvement for NHPT; the improvement in the experimental group was signifi- cant. It is known that "anticipatory" postural responses to counteract the effect of dynamic reactive forces are initiated before the onset of contraction of the muscles responsible for movement of the limb [33]. The anticipatory response of the trunk muscles is associated with movement of the upper limb. Contraction of either the erector spinae before upper-limb flexion or contraction of the rectus abdominis preceding upper-limb extension were shown [34].

Studies have also pointed out the relationship between trunk and upper-limb coordination when the target is located either at arm's length [35] or beyond arm's length [36-37]. Trunk movements were minimal when the target could be reached at arm's length; however, for objects located out of arm's reach, trunk motion contributed significantly to the transport phase of the hand. From the literature, it is known that rapid movement of the limbs is associated with contraction of the abdominal muscles before or shortly after contraction of the muscles responsible for initiation of the limb movement [38]. Our data emphasize the supportive role of trunk exercises on fast, voluntary limb movements. No statistical change was observed in cognitive scores, likely because there was no special exercise for cognitive functions. 


\section{CONCLUSIONS}

Based on the results of the present pilot study, exercises for trunk control are as effective as the limb exercises commonly used in neurorehabilitation programs. According to these results, trunk exercises based on the Bobath concept may be another option when the physiotherapist needs to vary the exercise program in clinical practice. It was concluded that inclusion of the exercises for trunk control in physical therapy and rehabilitation would have additional benefits.

\section{ACKNOWLEDGMENTS}

\section{Author Contributions:}

Study concept and design: I. Keser, N. Kirdi, R. Karabudak. Acquisition of data: I. Keser.

Analysis and interpretation of data: I. Keser, A. Meric, N. Kirdi.

Drafting of manuscript: I. Keser, A. T. Kurne, N. Kirdi.

Critical revision of manuscript for important intellectual content:

I. Keser, N. Kirdi, A. T. Kurne.

Statistical analysis: I. Keser, A. Meric.

Administrative, technical, or material support: N. Kirdi, R. Karabudak, I. Keser, A. T. Kurne, A. Meric.

Study supervision: N. Kirdi.

Financial Disclosures: The authors have declared that no competing interests exist.

Funding/Support: This material was based on work performed as part of a doctoral thesis and was supported by the Hacettepe University of Scientific Research and Development Unit.

Additional Contributions: Since completion of the study, Ilke Keser's affiliation changed from the Department of Physical Therapy and Rehabilitation, Faculty of Health Sciences, Hacettepe University, to the Department of Physical Therapy and Rehabilitation, Faculty of Health Sciences, Gazi University.

Institutional Review: The study was approved by the Ethical Committee of Hacettepe University. Participants were informed of the experimental procedures and signed a consent form approved by the university's institutional ethical committee.

Participant Follow-Up: The authors do not plan to inform participants of the publication of this study. However, all participants were previously informed that the data would be published in a scientific journal.

\section{REFERENCES}

1. Oken BS, Kishiyama S, Zajdel D, Bourdette D, Carlsen J, Haas M, Hugos C, Kraemer DF, Lawrence J, Mass M. Randomized controlled trial of yoga and exercise in multiple sclerosis. Neurology. 2004;62(11):2058-64.

\section{[PMID:15184614]}

http://dx.doi.org/10.1212/01.WNL.0000129534.88602.5C

2. Petajan JH, Gappmaier E, White AT, Spencer MK, Mino L, Hicks RW. Impact of aerobic training on fitness and quality of life in multiple sclerosis. Ann Neurol. 1996;39(4):432-41. [PMID:8619521]

http://dx.doi.org/10.1002/ana.410390405

3. Foerster O. Handbuch der Neurologie. Allgemeine Neurologie. 1936;8:316-414. German.

4. Dalgas U, Stenager E, Jakobsen J, Petersen T, Hansen HJ, Knudsen C, Overgaard K, Ingemann-Hansen T. Resistance training improves muscle strength and functional capacity in multiple sclerosis. Neurology. 2009;73(18):1478-84. [PMID:19884575] http://dx.doi.org/10.1212/WNL.0b013e3181bf98b4

5. Davies PM. Right in the middle: Selective trunk activity in the treatment of adult hemiplegia. Berlin Heidelberg (Germany): Springer-Verlag; 1990. p. 31-65.

6. Verheyden G, Nuyens G, Nieuwboer A, Van Asch P, Ketelaer P, De Weerdt W. Reliability and validity of trunk assessment for people with multiple sclerosis. Phys Ther. 2006;86(1):66-76. [PMID:16386063]

7. Cattaneo D, Jonsdottir J, Zocchi M, Regola A. Effects of balance exercises on people with multiple sclerosis: a pilot study. Clin Rehabil. 2007;21(9):771-81.

[PMID:17875557] http://dx.doi.org/10.1177/0269215507077602

8. Motl RW, Snook EM, Hinkle ML. Effect of acute unloaded leg cycling on spasticity in individuals with multiple sclerosis using anti-spastic medications. Int J Neurosci. 2007; 117(7):895-901. [PMID:17613103] http://dx.doi.org/10.1080/00207450600910671

9. Raine S. The current theoretical assumptions of the Bobath concept as determined by the members of BBTA. Physiother Theory Pract. 2007;23(3):137-52. [PMID:17558878] http://dx.doi.org/10.1080/09593980701209154

10. Bergmark A. Stability of the lumbar spine. A study in mechanical engineering. Acta Orthop Scand Suppl. 1989; 230:1-54. [PMID:2658468]

11. Verheyden G, Vereeck L, Truijen S, Troch M, Lafosse C, Saeys W, Leenaerts E, Palinckx A, De Weerdt W. Additional exercises improve trunk performance after stroke: a pilot randomized controlled trial. Neurorehabil Neural Repair. 2009;3(3):281-86. [PMID:18955513] http://dx.doi.org/10.1177/1545968308321776

12. Bartolo M, Serrao M, Tassorelli C, Don R, Ranavolo A, Draicchio F, Pacchetti C, Buscone S, Perrotta A, Furnari A, Bramanti P, Padua L, Pierelli F, Sandrini G. Four-week trunk-specific rehabilitation treatment improves lateral trunk flexion in Parkinson's disease. Mov Disord. 2010; 25(3):325-31. [PMID:20131386] http://dx.doi.org/10.1002/mds.23007 
13. Lanzetta D, Cattaneo D, Pellegatta D, Cardini R. Trunk control in unstable sitting posture during functional activities in healthy subjects and patients with multiple sclerosis. Arch Phys Med Rehabil. 2004;85(2):279-83. [PMID:14966714] http://dx.doi.org/10.1016/j.apmr.2003.05.004

14. Smedal T, Lygren H, Myhr KM, Moe-Nilssen R, Gjelsvik $\mathrm{B}$, Gjelsvik O, Strand LI. Balance and gait improved in patients with MS after physiotherapy based on the Bobath concept. Physiother Res Int. 2006;11(2):104-16.

[PMID:16808091] http://dx.doi.org/10.1002/pri.327

15. Hobart J, Freeman J, Thompson A. Kurtzke scales revisited: the application of psychometric methods to clinical intuition. Brain. 2000;123(Pt 5):1027-40. [PMID:10775547] http://dx.doi.org/10.1093/brain/123.5.1027

16. Mount J, Dacko S. Effects of dorsiflexor endurance exercises on foot drop secondary to multiple sclerosis: a pilot study. NeuroRehabilitation. 2006;21(1):43-50. [PMID:16720937]

17. Sackett DL, Rosenberg WM, Gray JA, Haynes RB, Richardson WS. Evidence based medicine: what it is and what it isn't. BMJ. 1996;312(7023):71-72. [PMID:8555924] http://dx.doi.org/10.1136/bmj.312.7023.71

18. Berg KO, Maki BE, Williams JI, Holliday PJ, WoodDauphinee SL. Clinical and laboratory measures of postural balance in an elderly population. Arch Phys Med Rehabil. 1992;73(11):1073-80. [PMID:1444775]

19. Cattaneo D, Regola A, Meotti M. Validity of six balance disorders scales in persons with multiple sclerosis. Disabil Rehabil. 2006;28(12):789-95. [PMID:16754576] http://dx.doi.org/10.1080/09638280500404289

20. Cattaneo D, Jonsdottir J, Repetti S. Reliability of four scales on balance disorders in persons with multiple sclerosis. Disabil Rehabil. 2007;29(24):1920-25.

[PMID:17852286] http://dx.doi.org/10.1080/09638280701191859

21. Trouillas P, Takayanagi T, Hallett M, Currier RD, Subramony SH, Wessel K, Bryer A, Diener HC, Massaquoi S, Gomez CM, Coutinho P, Ben Hamida M, Campanella G, Filla A, Schut L, Timann D, Honnorat J, Nighoghossian N, Manyam B; The Ataxia Neuropharmacology Committee of the World Federation of Neurology. International Cooperative Ataxia Rating Scale for pharmacological assessment of the cerebellar syndrome. J Neurol Sci. 1997;145(2):205-11. [PMID:9094050] http://dx.doi.org/10.1016/S0022-510X(96)00231-6

22. Schmitz-Hübsch T, Tezenas du Montcel S, Baliko L, Boesch S, Bonato S, Fancellu R, Giunti P, Globas C, Kang JS, Kremer B, Mariotti C, Melegh B, Rakowicz M, Rola R, Romano S, Schöls L, Szymanski S, van de Warrenburg BP, Zdzienicka E, Dürr A, Klockgether T. Reliability and valid- ity of the International Cooperative Ataxia Rating Scale: a study in 156 spinocerebellar ataxia patients. Mov Disord. 2006;21(5):699-704. [PMID:16450347]

http://dx.doi.org/10.1002/mds.20781

23. Schoch B, Regel JP, Frings M, Gerwig M, Maschke M, Neuhäuser M, Timmann D. Reliability and validity of ICARS in focal cerebellar lesions. Mov Disord. 2007; 22(15):2162-69. [PMID:17712842] http://dx.doi.org/10.1002/mds.21543

24. Storey E, Tuck K, Hester R, Hughes A, Churchyard A. Inter-rater reliability of the International Cooperative Ataxia Rating Scale (ICARS). Mov Disord. 2004;19(2): 190-92. [PMID:14978674] http://dx.doi.org/10.1002/mds.10657

25. Keser İ, Kırdı N. Multipl Skleroz'da Uluslararası Ataksi Oranlama Ölçeği Klinikte Kullanışlı Bir Araç mıdır? Fizyoterapi Rehabilitasyon. 2008;19:192. Turkish.

26. Ozakbas S, Cagiran I, Ormeci B, Idiman E. Correlations between multiple sclerosis functional composite, expanded disability status scale and health-related quality of life during and after treatment of relapses in patients with multiple sclerosis. J Neurol Sci. 2004;218(1-2):3-7. [PMID:14759626] http://dx.doi.org/10.1016/j.jns.2003.09.015

27. Rosti-Otajärvi E, Hämäläinen $P$, Koivisto K, Hokkanen L. The reliability of the MSFC and its components. Acta Neurol Scand. 2008;117(6):421-27. [PMID:18081910] http://dx.doi.org/10.1111/j.1600-0404.2007.00972.x

28. Kraft GH. Rehabilitation still the only way to improve function in multiple sclerosis. Lancet. 1999;354(9195): 2016-17. [PMID:10636362] http://dx.doi.org/10.1016/S0140-6736(99)90035-1

29. Collin C, Wade D. Assessing motor impairment after stroke: a pilot reliability study. J Neurol Neurosurg Psychiatry. 1990;53(7):576-79. [PMID:2391521] http://dx.doi.org/10.1136/jnnp.53.7.576

30. Hodges PW, Butler JE, McKenzie DK, Gandevia SC. Contraction of the human diaphragm during rapid postural adjustments. J Physiol. 1997;505(Pt 2):539-48.

[PMID:9423192]

http://dx.doi.org/10.1111/j.1469-7793.1997.539bb.x

31. Hodges PW, Cresswell AG, Daggfeldt K, Thorstensson A. Three dimensional preparatory trunk motion precedes asymmetrical upper limb movement. Gait Posture. 2000; 11(2):92-101. [PMID:10899662] http://dx.doi.org/10.1016/S0966-6362(99)00055-7

32. Teyssèdre $\mathrm{C}$, Lino F, Zattara M, Bouisset S. Anticipatory EMG patterns associated with preferred and non-preferred arm pointing movements. Exp Brain Res. 2000;134(4): 435-40. [PMID:11081825] http://dx.doi.org/10.1007/s002210000490 
33. Cordo PJ, Nashner LM. Properties of postural adjustments associated with rapid arm movements. J Neurophysiol. 1982;47(2):287-302. [PMID:7062101]

34. Aruin AS, Latash ML. Directional specificity of postural muscles in feed-forward postural reactions during fast voluntary arm movements. Exp Brain Res. 1995;103(2):323-32. [PMID:7789439] http://dx.doi.org/10.1007/BF00231718

35. Adamovich SV, Archambault PS, Ghafouri M, Levin MF, Poizner H, Feldman AG. Hand trajectory invariance in reaching movements involving the trunk. Exp Brain Res. 2001;138(3):288-303. [PMID:11460767] http://dx.doi.org/10.1007/s002210100694

36. Kaminski TR, Bock C, Gentile AM. The coordination between trunk and arm motion during pointing movements. Exp Brain Res. 1995;106(3):457-66. [PMID:8983989] http://dx.doi.org/10.1007/BF00231068

37. Tyler AE, Hasan Z. Qualitative discrepancies between trunk muscle activity and dynamic postural requirements at the initiation of reaching movements performed while sitting. Exp Brain Res. 1995;107(1):87-95. [PMID:8751066] http://dx.doi.org/10.1007/BF00228020
38. Hodges PW, Richardson CA. Feedforward contraction of transversus abdominis is not influenced by the direction of arm movement. Exp Brain Res. 1997;114(2):362-70. [PMID:9166925] http://dx.doi.org/10.1007/PL00005644

Submitted for publication December 5, 2011. Accepted in revised form May 18, 2012.

This article and any supplementary material should be cited as follows:

Keser I, Kirdi N, Meric A, Kurne AT, Karabudak R. Comparing routine neurorehabilitation program with trunk exercises based on Bobath concept in multiple sclerosis: Pilot study. J Rehabil Res Dev. 2013;50(1):133-40. http://dx.doi.org/10.1682/JRRD.2011.12.0231

ResearcherID: Ilke Keser, PhD, PT: A-8715-2013

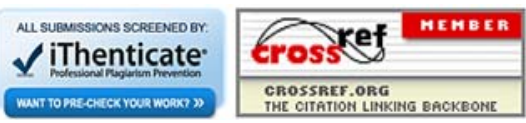

